\title{
Editorial
}

\section{Provision and Guidance for Postpartum Contraception - Ensuring Reproductive Rights during Times of Crises}

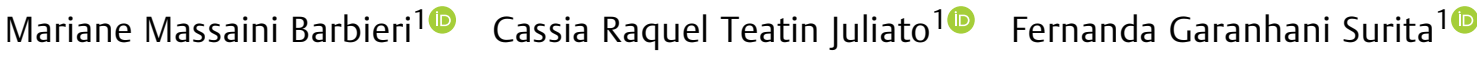 \\ 1 Universidade Estadual de Campinas, Campinas, SP, Brazil
}

Rev Bras Ginecol Obstet 2021;43(4):247-249.

Reproductive choice and access to contraception are basic rights for all women, representing a major step forward in the improvement of gender equality. Sexual and reproductive health is paramount when considering public health, and has been directly affected by the COVID-19 pandemic, since these services suffered a reduction in their capacity for elective care, including consultations directed at contraceptive counseling. ${ }^{1}$ This could lead to increase in the number of unplanned pregnancies, which has already been reported as above $50 \%$ of all pregnancies.

Postpartum contraception should be considered as an essential component of obstetric care. The immediate postpartum period, prior to hospital discharge is an excellent opportunity to counseling and providing contraceptives, particularly in those women who are unable to attend their follow-up appointments six weeks postpartum. ${ }^{2}$ Approximately $40 \%$ of women do not attend their postpartum appointments, which favors an increased rate of unplanned and rapid repeated pregnancies (those which occur at intervals of fewer than 18 months). 3,4

Unplanned pregnancies strongly impact various aspects of women's lives, even more so when they occur during adolescence. A Brazilian study showed that women who fell pregnant between 16 and 19 years of age had lower schooling levels compared to those who did not fall pregnant [-2.8 years ( $95 \% \mathrm{CI}$ : -3.2 to -2.3 )], which was even more significant when pregnancy occurred between 11 and 15 years of age [-4.4 years ( $95 \% \mathrm{CI}$ : -5.5 to -3.3$)$ ]. These effects were more evident in women with three or more children. Income at 30 years of age was also $49 \%$ or $33 \%$ lower in women whose first child was born between $16-19$ or $11-15$ years old, respectively. ${ }^{5}$

The new coronavirus pandemic has lead to emergency care services being prioritized in an attempt to reduce morbidity and mortality. Maternity hospitals have attempted to maintain humanized care during childbirth, which has highlighted their importance in approaching women and offering health education with an emphasis on reproductive health, specifically safe and effective postpartum contraception. ${ }^{6}$ Ideally, counseling

Address for correspondence Fernanda Garanhani Surita,

Cidade Universitária Zeferino Vaz,

Campinas, SP, 13083-970, Brazil

(e-mail: surita@unicamp.br). on available contraceptive methods should begin during antenatal care, via focus groups or during individual appointments. ${ }^{7}$ Unfortunately, group activities have been restricted due to the need for social distancing, and the issue of postpartum contraception has not always been considered a priority during individual consultations. Therefore, the immediate postpartum period is an opportune and often unique moment to approach this important topic.

All available contraceptive methods that are considered appropriate for use during the postpartum period (etonogestrel (ENG) subdermal implants, intrauterine devices (IUDs), Depot Medroxyprogesterone Acetate and the progestogenonly pill) should be offered to women, with clear explanations of their advantages and disadvantages, duration of action, and the possibility of interruption or removal of the method according to patients' wishes. ${ }^{8}$ All methods would ideally be presented through photos or posters, and in different orders so as to minimize coercion or promotion of one method over another. The counseling process must allow the woman free choice. $^{9}$

Long-acting reversible contraception (LARC) methods, such as ENG-implants and IUDs (which includes cooper IUD and levonorgestrel intrauterine releasing system) are considered the first choice for women. ${ }^{10}$ LARCs are the most effective contraceptive methods, with a pregnancy rate of less than 1/1000 women/year, a higher degree of user satisfaction and higher continuation rates. Several international institutions, including the World Health Organization (WHO) and International Federation of Gynecology and Obstetrics (FIGO), recommend their introduction during the immediate postpartum period, as it presents a moment in which women are motivated to prevent new pregnancies, allowing hospital discharge with prevention methods in place. ${ }^{11}$ It is important to highlight that this does not exempt the women from their postpartum follow-up appointments, which are mandatory and provide several other functions. ${ }^{12}$

Post-placental intrauterine device insertion is an effective method for preventing unplanned and recurrent pregnancies,
(C) 2021. Federação Brasileira de Ginecologia e Obstetrícia. All rights reserved.

This is an open access article published by Thieme under the terms of the Creative Commons Attribution License, permitting unrestricted use, distribution, and reproduction so long as the original work is properly cited. (https://creativecommons.org/licenses/by/4.0/)

Thieme Revinter Publicações Ltda., Rua do Matoso 170, Rio de Janeiro, RJ, CEP 20270-135, Brazi 
as well as to reduce healthcare visits, reducing costs and risks due to the pandemic. A study carried out in our service revealed that almost two thirds of women who opted for insertion of a post-placental IUD chose to maintain its use after one year. ${ }^{13}$ Spontaneous expulsion of the IUD was the main reason for discontinued use. Another study showed that the insertion of post-placental IUDs prevented 88 pregnancies for every 100 women during a follow-up period of two years. The main disadvantage of post-placental intrauterine contraception is the higher expulsion rate, when compared to insertion after 40 days postpartum. However, a cost-benefit advantage is still considered. ${ }^{14}$ Despite the practice of offering post-placental IUDs being routine in some settings, patient acceptance is still limited, most likely due to myths surrounding the use of IUDs, which are even more evident when considering the immediate postpartum period. It is important to highlight that some women present contraindications to IUD placement. Other considerations include, when prior counseling has not been offered, when time to allow the patient to consider the method is lacking, or should the healthcare team have limitations in offering any method at the opportune moment due to large numbers of simultaneous procedures or emergency situations. The insertion of a post-placental IUD is simple and safe, and requires minimum training, which is frequently offered by specialty college courses.

The ENG-implant is the most effective method, with a failure rate of $0.05 \%$. It provides safe and long-term contraception in postpartum women, and does not interfere with breastfeeding or infant weight gain. ${ }^{15}$ Studies relating to ENG-implant acceptance within the immediate postpartum period are few and far between in the scientific literature. A recent study performed during the peak of the first wave of coronavirus infection in Brazil, involving 151 women aged up to 24 years of age, showed high acceptance $(76.2 \%) .{ }^{16}$ The main disadvantage of the subdermal implant is its high cost; hence it is not routinely offered by healthcare services. During the immediate postpartum period, the principal advantage of the subdermal implant when compared to the IUD is the time scale in which a decision needs to be made regarding insertion, allowing the woman to make a more conscious decision. This is important when no prior antenatal counseling has been offered, as the woman has more time to consider and discuss her options, since the implant placement can be performed at any time before the hospital discharge. Insertion of the implant is simple and safe, however adequate training is required. ${ }^{16,17}$

Assessment of risk/benefit, as well as other factors regarding the impact of hormonal contraception while breastfeeding must be considered. The WHO eligibility criteria show that the risk of using Depot Medroxyprogesterone Acetate in women less than 6 weeks postpartum outweighs the benefits (category 3 ). ${ }^{18}$ Although there are some extenuating circumstances where its use during the immediate postpartum period has been reported, ${ }^{19}$ it is more appropriate to advise and discharge women with a prescription for its use starting 6 weeks after delivery. Progesterone only pills may be started at any time after delivery. $^{12}$
The Lactational Amenorrhea Method (LAM) can be used in women who exclusively breastfeed on demand for up to six months postpartum, so long as they continue amenorrheic. Despite exclusive breastfeeding during this period, 20 to 56\% of women restart menstruating earlier, decreasing its effectiveness. ${ }^{20}$

During the first six weeks postpartum, barrier methods (male and female condoms) can be used without restriction. Their use should always be encouraged to prevent sexually transmitted diseases. ${ }^{8}$

Difficulty in accessing health services and quality contraception in times of crisis negatively affects the reproductive health and life of women, especially vulnerable groups. The immediate postpartum period is important for implementation of reproductive healthcare, including counseling and the provision of contraceptive methods, such as the LARC, which has a long duration and is highly effective. ${ }^{10}$ Offering other methods allows women a choice of the method as well the time scale to begin its use. This leads to better adherence, lower rates of unplanned and recurrent pregnancies, a more adequate interval between births and decreased maternal and child mortality. ${ }^{9}$ Therefore, reproductive health counseling is a fundamental tool for health promotion. One should emphasize that maternal mortality has taken on a catastrophic dimension in Brazil during the coronavirus pandemic. ${ }^{21}$

During a long pandemic such as in the current climate, which has required the restructuring of healthcare services to focus almost exclusively on coronavirus infection, the adequate advice on contraceptive methods for women in the postpartum period prior to hospital discharge is an essential tool to guarantee the health and rights of reproductive choice of each woman.

\section{Conflicts to Interest}

The authors have no conflict of interests to declare.

\section{References}

1 Bahamondes L, Makuch MY. Family planning: an essential health activity in the pandemic of SARS-CoV-2. Eur J Contracept Reprod Health Care. 2020;25(04):319-320. Doi: 10.1080/13625187.2020. 1768368

2 McKinney J, Keyser L, Clinton S, Pagliano C. ACOG Committee Opinion No. 736: optimizing postpartum care. Obstet Gynecol. 2018;132(03):784-785. Doi: 10.1097/AOG.0000000000002849

3 Bryant AS, Haas JS, McElrath TF, McCormick MC. Predictors of compliance with the postpartum visit among women living in healthy start project areas. Matern Child Health J. 2006;10(06): 511-516. Doi: 10.1007/s10995-006-0128-5

4 Floyd S. Postpartum contraception options. Obstet Gynecol Clin North Am. 2020;47(03):463-475. Doi: 10.1016/j.ogc.2020.04.007

5 Gigante DP, de França G, De Lucia ERolfe, Lima NP, Dos Santos JVMotta, Gonçalves H, et al. Adolescent parenthood associated with adverse socio-economic outcomes at age 30 years in women and men of the Pelotas, Brazil: 1982 Birth Cohort Study. BJOG. 2019;126(03):360-367. Doi: 10.1111/1471-0528.15428

6 Surita FGC, Luz AG, Hsu LPR, Carvalho FHC, Brock MF, Nakamura MU. Outpatient care for pregnant and puerperal women during the COVID-19 pandemic. Rev Bras Ginecol Obstet. 2020;42(09): 588-592. Doi: 10.1055/s-0040-1718473

7 WHO Recommendations on Antenatal Care for a Positive Pregnancy Experience. Geneva: World Health Organization; 2016 
8 Chen MJ, Kim CR, Whitehouse KC, Berry-Bibee E, Gaffield ME. Development, updates, and future directions of the World Health Organization selected practice recommendations for contraceptive Use. Int J Gynaecol Obstet. 2017;136(02):113-119. Doi: 10.1002/ijgo.12064

9 Berlan ED, Richards MJ, Vieira CS, Creinin MD, Kaunitz AM, Fraser IS, et al. Best practices for counseling adolescents about the etonogestrel implant. J Pediatr Adolesc Gynecol. 2020;33(05): 448-454. Doi: 10.1016/j.jpag.2020.06.022

10 Brunson MR, Klein DA, Olsen CH, Weir LF, Roberts TA. Postpartum contraception: initiation and effectiveness in a large universal healthcare system. Am J Obstet Gynecol. 2017;217(01):55.e1-55. e9. Doi: 10.1016/j.ajog.2017.02.036

11 Qasba NT, Stutsman JW, Weaver GE, Jones KE, Daggy JK, Wilkinson TA. Informing policy change: a study of rapid repeat pregnancy in adolescents to increase access to immediate postpartum contraception. J Womens Health (Larchmt). 2020;29(06): 815-818. Doi: 10.1089/jwh.2019.8122

12 Curtis KM, Tepper NK, Jatlaoui TC, Berry-Bibee E, Horton LG, Zapata LB, et al. U.S. Medical eligibility criteria for contraceptive use, 2016. MMWR Recomm Rep. 2016;65(03):1-103. Doi: 10.15585/mmwr.rr6503a1

13 Marangoni M Jr, Laporte M, Surita F, Kraft MB, Bahamondes L, Juliato CRT. One-year follow up on post-placental IUD insertion: A randomized clinical trial. Acta Obstet Gynecol Scand. 2021;100 (04):596-603. Doi: 10.1111/aogs.14081

14 Makins A, Taghinejadi N, Sethi M, Machiyama K, Munganyizi P, Odongo E, et al. FIGO postpartum intrauterine device initiative: Complication rates across six countries. Int J Gynaecol Obstet. 2018;143(Suppl 1):20-27. Doi: 10.1002/ijgo.12600
15 Braga GC, Ferriolli E, Quintana SM, Ferriani RA, Pfrimer K, Vieira CS. Immediate postpartum initiation of etonogestrel-releasing implant: A randomized controlled trial on breastfeeding impact. Contraception. 2015;92(06):536-542. Doi: 10.1016/j.contraception.2015.07.009

16 Barbieri MM, Herculano T, Dantas Silva A, Bahamondes L, Juliato CRT, Surita FG. Acceptability of ENG-releasing subdermal implants before discharge in Brazilian young women during the COVID-19 pandemic. Int J Gynaecol Obstet. 2021;œ..;. Doi: 10.1002/ijgo.13663[ahead of print]

17 Griffin L, Hammond C, Liu D, Rademaker AW, Kiley J. Postpartum weight loss in overweight and obese women using the etonogestrel subdermal implant: a pilot study. Contraception. 2017;95 (06):564-570. Doi: 10.1016/j.contraception.2017.02.020

18 Cravioto MD. [New recommendations from the World Health Organization (WHO) for the use of contraceptive methods]. Gac Med Mex. 2016;152(05):601-603Spanish.

19 Dozier AM, Nelson A, Brownell EA, Howard CR, Lawrence RA. Patterns of postpartum depot medroxyprogesterone administration among low-income mothers. J Womens Health (Larchmt). 2014;23(03):224-230. Doi: 10.1089/jwh.2012.4016

20 Van der Wijden C, Manion C. Lactational amenorrhoea method for family planning. Cochrane Database Syst Rev. 2015;(10): CD001329. Doi: 10.1002/14651858

21 Nakamura-Pereira M, Knobel R, Menezes MO, Andreucci CB, Takemoto MLS. The impact of the COVID-19 pandemic on maternal mortality in Brazil: 523 maternal deaths by acute respiratory distress syndrome potentially associated with SARS-CoV-2. Int J Gynaecol Obstet. 2021;153(02):360-362. Doi: 10.1002/ ijgo.13643 